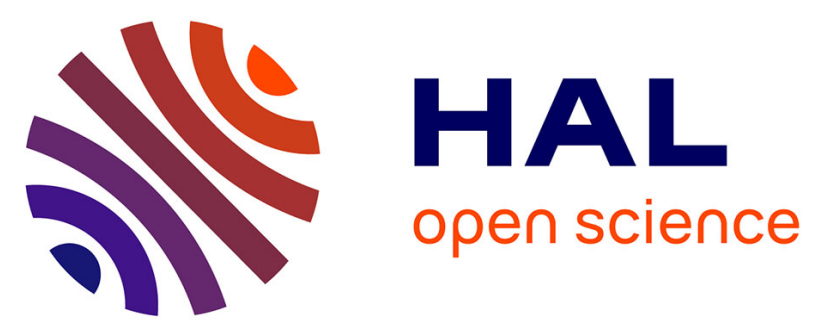

\title{
Self-Assembly of Mitochondria-Specific Peptide Amphiphiles Amplifying the Lung Cancer Cell Death through Targeting the VDAC1-Hexokinase-II Complex
}

Dan Liu, Angelina Angelova, Jianwen Liu, Vasil M Garamus, Borislav

Angelov, Xinlei Zhang, Yawen Li, Guillaume Feger, Na Li, Aihua Zou

\section{To cite this version:}

Dan Liu, Angelina Angelova, Jianwen Liu, Vasil M Garamus, Borislav Angelov, et al.. Self-Assembly of Mitochondria-Specific Peptide Amphiphiles Amplifying the Lung Cancer Cell Death through Targeting the VDAC1-Hexokinase-II Complex. Journal of materials chemistry B, 2019, 7 (30), pp.4706-4716. $10.1039 / \mathrm{c} 9 \mathrm{tb} 00629 \mathrm{j}$. hal-02381244

\section{HAL Id: hal-02381244 \\ https://hal.science/hal-02381244}

Submitted on 26 Nov 2019

HAL is a multi-disciplinary open access archive for the deposit and dissemination of scientific research documents, whether they are published or not. The documents may come from teaching and research institutions in France or abroad, or from public or private research centers.
L'archive ouverte pluridisciplinaire HAL, est destinée au dépôt et à la diffusion de documents scientifiques de niveau recherche, publiés ou non, émanant des établissements d'enseignement et de recherche français ou étrangers, des laboratoires publics ou privés. 
Received Accepted

DOI:

\title{
Self-Assembly of Mitochondria-Specific Peptide Amphiphiles Amplifying the Lung Cancer Cell Death through Targeting the VDAC1-Hexokinase-II Complex
}

\author{
Dan Liu, ${ }^{a}$ Angelina Angelova, ${ }^{b}$ Jianwen Liu, ${ }^{c}$ Vasil M. Garamus, ${ }^{d}$ Borislav Angelov, ${ }^{e}$ Xinlei Zhang, ${ }^{a}$ \\ Yawen Li, ${ }^{a}$ Guillaume Feger, ${ }^{b} \mathrm{Na} \mathrm{Li},{ }^{f}{ }^{\mathrm{A}}$ ihua Zou*a
}

\begin{abstract}
Mitochondria-targeting peptides represent an emergent approach for cancer inhibition. Here supramolecular assemblies of novel amphiphilic cell-penetrating peptides for targeting cancer cells mitochondria are reported. The employed strategy aims at amplifying the apoptotic stimuli by weakening the mitochondrial VDAC1 (voltage-dependent anion channel-1)hexokinase-II (HK-II) interaction. Peptide engineering is performed with the N-terminus of the HK-II protein, which binds to VDAC1. First, a designed positively-charged segment (pKV) is anchored to the specific 15 aminoacid sequence (MIASHLLAYFFTELN) to yield a cell-penetrating peptide (pHK-pKV). Second, a lipid chain (Pal) is conjugated to the Nterminus of pHK-pKV in order to enhance the intracellular delivery of the HK-II scaffold. The self-assembly properties of these two synthetic peptides are investigated by synchrotron small-angle X-ray scattering (BioSAXS) and cryogenic transmission electron (cryo-TEM) imaging, which evidence the formation of nanoassemblies of ellipsoid-like shapes. Circular dichroism (CD) spectroscopy demonstrates the induction of partial $\alpha$-helical structures in the amphiphilic peptides. Confocal microscopy reveals the specific mitochondrial location of Pal-pHK-pKV assemblies in human non-small cell lung cancer (NSCLC) A549 cells. The cytotoxicity and apoptotic studies indicate the enhanced bioactivity of Pal-pHK-pKV selfassembled reservoirs, which cause massive A549 cell death with regard to pHK-pKV. Whereas the half maximum inhibitory concentration $\left(\mathrm{IC}_{50}\right.$ ) of the Pal-pHK-pKV peptide conjugates is $6.5 \mu \mathrm{M}$ in the $\mathrm{A} 549$ cancer cell line, it is higher than $50 \mu \mathrm{M}$ for healthy human mucosal epithelial cells such as the non-cancerous NCM460 cells. The results demonstrate the potential of self-assembled lipo-peptide (HK-II-derived) conjugates as a promising strategy in cancer therapy.
\end{abstract}

\section{Introduction}

Cancer cell mitochondria are recognized as important targets for inhibition of the cancer progression in anti-cancer therapies. ${ }^{1-3}$ They currently underlie new drug developments,

\footnotetext{
a. Shanghai Key Laboratory of Functional Materials Chemistry, State Key Laboratory of Bioreactor Engineering and Institute of Applied Chemistry, School of Chemistry and Molecular Engineering, East China University of Science and Technology, Shanghai 200237, P. R. China.

b. Institut Galien Paris-Sud, CNRS UMR 8612, LabEx LERMIT, Univ. Paris-Sud, Université Paris-Saclay, F-92296 Châtenay-Malabry, France.

State Key Laboratory of Bioreactor Engineering \& Shanghai Key Laboratory of New Drug Design, School of Pharmacy, East China University of Science and Technology, Shanghai 200237, PR China.

d. Helmholtz-Zentrum Geesthacht: Centre for Materials and Coastal Research, $D$ 21502 Geesthacht, Germany.

e. Institute of Physics, ELI Beamlines, Academy of Sciences of the Czech Republic, Na Slovance 2, CZ-18221 Prague, Czech Republic.

f. National Center for Protein Science Shanghai and Shanghai Institute of Biochemistry and Cell Biology, Shanghai 201210, P. R. China.

† East China University of Science and Technology.

*To whom correspondence should be addressed.

E-mail: aihuazou@ecust.edu.cn

E-mail: $\underline{\text { nli@sibcb.ac.cn }}$
}

which will complement the existing therapies for cancer cells killing and cancer elimination. ${ }^{4-12}$ The mitochondrial-targeting anti-cancer mechanisms include the activation of mitochondria-mediated apoptotic pathways via voltagedependent-anion-channel (VDAC) targeting agents or electron transport/respiratory chain blockers, ${ }^{13-15}$ the increased induction of reactive oxygen species (ROS), ${ }^{16,17}$ the inhibition of the $\mathrm{Bcl}-2$ anti-apoptotic family of proteins, ${ }^{18}$ the activation of the mitochondrial membrane permeability transition pore protein subunits, ${ }^{19,20}$ the mtDNA targeting in cancer cells, ${ }^{19}$ and treatments involving mitochondrial destabilization, mitochondrial membrane permeabilization, ${ }^{21}$ mitochondrial fission and massive mitochondrial fragmentation using lipophilic cations targeting the inner membrane. ${ }^{22-28}$

Hexokinase-II (HK-II) is increasingly regarded as an attractive therapeutic target for cancer therapy based on its key role in glycolysis as a part of the cell energy metabolism. ${ }^{29,30}$ The mitochondrial metabolism of cancer cells is deregulated, the glucose metabolism being enhanced and the mitochondrial oxidative phosphorylation reduced. HK-II is the enzyme that catalyses the phosphorylation of glucose, which is the rate-limiting first step of glycolysis (i.e. glucose degradation). ${ }^{31,32}$ The expression levels of the HK-II protein in aggressive cancer cells are considerably higher than those in normal cells. ${ }^{33}$ Owing to the fact that mitochondria-bound HKII is less responsive to inhibition by its glucose-6-phosphate product, the mitochondrial binding of HK-II conserves a higher rate of glycolysis in cancer cells. ${ }^{34}$ At the same time, the overexpression of mitochondria-bound HK-II prevents cancer cells from death by retaining the integrity of the mitochondria and inhibiting the release of cytochrome C. ${ }^{35-37}$ Consequently, recent studies have suggested that $\mathrm{HK}-\mathrm{II}$ can be a valuable therapeutic target for cancer treatment due to its overexpression in cancer cells and its involvement in the 
metabolic reprogramming. ${ }^{38-40}$ Different strategies have been envisioned for HK-II targeting towards triggering of mitochondria-specific killing of cancer cells. Silencing of the HK-II transcript has been shown to induce apoptosis in cancer cells. $^{37}$

Importantly, the hexokinase isoform HK-II binds the voltage-dependent anion channel 1 (VDAC1), which is located at the outer mitochondrial membrane (OMM). ${ }^{41}$ VDAC1 is a multi-functional membrane protein channel providing the exchange of ions and metabolites between the mitochondria and the cytosol. ${ }^{42}$ VDAC1 interacts with anti-apoptotic proteins and plays a key role in the mitochondria-mediated apoptosis. The association of the proteins VDAC1 and HK-II promotes the inhibition of apoptosis. ${ }^{43}$ Therefore, either the hampering of the HK-II binding to the OMM or the dissociation of the VDAC1-hexokinase HK-II complex should enable the activation of the cancer cell apoptosis. ${ }^{44.45}$ This emergent approach is expected to contribute for overcoming the drug resistance problem in anti-cancer treatments.

Table 1. Peptide sequences and their basic characteristics.

\begin{tabular}{llcc}
\hline Peptide & Amino Acid Sequence & Molecular Weight & Net Charge \\
\hline pHK & MIASHLLAYFFTELN & 1770.0 & -1 \\
pHK-AMC & MIASHLLAYFFTELN-AMC & 1927.2 & -1 \\
pHK-pKV & MIASHLLAYFFTELN-KVLKQRAKKK & 2979.9 & +5 \\
pHK-pKV-AMC & MIASHLLAYFFTELNKVLKQRAKKK-AMC & 3135.2 & +4 \\
Pal-pHK-pKV & PaI-MIASHLLAYFFTELN-KVLKQRAKKK & 3217.2 & +5 \\
Pal-pHK-pKV-AMC & Pal-MIASHLLAYFFTELN-KVLKQRAKKK-AMC & 3373.75 & +4 \\
\hline
\end{tabular}

*AMC: 7-amino-4-methylcoumarin fluorescent label

The present work aims at further advancing the strategy for targeting the mitochondrial VDAC1-hexokinase HK-II interaction by studying bioactive amphiphilic peptide assemblies, which can reach the OMM and trigger the dissociation of the VDAC1-HK-II complex towards cancer cell apoptosis. The activity of the designed novel peptide amphiphiles for induction of specific mitochondria-mediated apoptosis was examined with the human non-small cell lung cancer (NSCLC) cell line (A549). A non-cancerous healthy human epithelial cell line NCM460 (normal human colon mucosa cells) was used as a control. We exploited the fact that the 15 aminoacid peptide sequence ( $\mathrm{pHK}$ ) from the $\mathrm{N}$-terminal of the HK-II protein (MIASHLLAYFFTELN) could dissociate the endogenous HK-II from the mitochondria and thus disrupt the VDAC1-hexokinase II interactions. ${ }^{41}$ However, the peptide fragment pHK appears to be impermeable to the cells and this hampers its application in anti-cancer therapies. ${ }^{43,44,46}$ Here, the problem of $\mathrm{pHK}$ peptide delivery inside the cancer cells will be solved through the generation of self-assembled nanocarriers with an enhanced capacity for internalization into the studied cells.

Self-assembling peptides have been designed and synthesized for a number of biomedical applications such as drug delivery, cell culture models of diseases, nanobiotechnology, nanostructured biomaterials, tissue engineering and regeneration, etc. ${ }^{47-54}$ Peptide self-assembly into organized supramolecular architectures helps improving the stability and the bioavailability of the peptide therapeutics. Certain physico-chemical parameters strongly affect the selfassembling capacities of the peptide macromolecules including the number and the location of the hydrophobic amino acids and the presence of charged residues that are influenced by the $\mathrm{pH}$ and the composition of the aqueous medium. ${ }^{55-57}$ Lipopeptides containing a sequence of positively-charged aminoacid residues and an anchored fatty acid tail tend to self- assemble into a variety of nanostructures such as nanotubes, nanorods, nanofibrils, nanotapes, nanospheres, etc. ${ }^{58-62}$ Modifying the amino-acid sequence and extending the hydrogen bonding, hydrophobic, electrostatic, $\pi-\pi$ interactions, and van der Waals interactions can affect the shapes of the formed nano-assemblies, ${ }^{63-65}$ their tendency to form three-dimensional networks, and their interactions with the biological membranes. ${ }^{66,67}$ Studies have indicated that the self-assembly state (monomer, dimer, oligomer...) and the nanoarchitecture type may influence the biological outcome of the peptide amphiphiles in in vitro and in vivo applications. ${ }^{68,69}$ Moreover, nanoscale delivery systems can be used for efficient protection, transport and delivery of the biomimetic scaffolds and drugs across the biomembrane barriers. ${ }^{70-78}$ SAXS analysis and cryo-TEM imaging are powerful and indispensable methods for the structural characterization of the selfassembled nanostructures and nanocarriers. ${ }^{79-85}$

The purpose of the present work is to investigate the selfassembly behaviour of novel amphiphilic peptides (pHK-pKV and Pal-pHK-pKV) and the cancer cell mitochondria-specific targeting by the nano-assemblies derived from the $\mathrm{N}$-terminus of the HK-II protein (pHK) (Table 1). Structural analysis of the supramolecular peptide assemblies is performed by synchrotron BioSAXS, cryo-TEM and circular dichroism spectroscopy experiments. The biological activity of the new peptide nano-assemblies is evaluated in vitro with the NSCLC cancer cell model (human A549 cell line) and compared to that in non-tumour cells. The advantage of the peptide amphiphile concept is that it combines (i) a drug delivery strategy for enhancement of the cellular permeability and uptake of pHK through its anchoring to a positively charged cell penetrating peptide pKV (KVLKQRAKKK), ${ }^{86}$ and (ii) the amplification of the cancer cell apoptotic process by nano-assemblies based on mitochondria-specific targeting and disruption of the HK-IIVDAC1 contact at the OMM. 


\section{Results and discussion}

Self-assembly properties of novel mitochondria-specific peptide amphiphiles

We performed structural investigations of the self-assembled nanostructures formation of the amphiphilic peptide derivatives pHK-pKV and Pal-pHK-pKV (Fig. 1). The starting point of the rationale of their design is the objective for targeting of the voltage-dependent-anion-channel (VDAC1)hexokinase-II complex at the OMM of cancer cells, where these proteins are overexpressed. The native sequence (pHK) of the N-terminal region of HK-II served as a template for the peptide synthesis (Table 1). In the lack of carrier systems, the capacity of the negatively charged pHK for internalization into cells is negligibly small. The pHK-pKV derivative (Fig.1) was constructed by adding of a short, positively charged peptide pKV at the C-terminus of pHK. The rationale of designing the cell-penetrating peptide ( $p K V)$ was considered in a separate work. ${ }^{86}$ The purpose here is to create peptide assemblies with enhanced cytotoxicity to cancer cells.

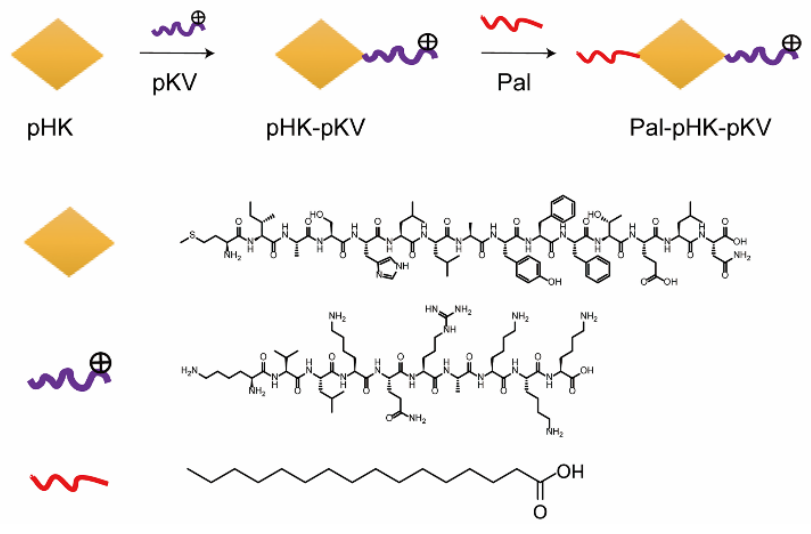

Fig. 1 Scheme of the building of amphiphilic cell-penetrating peptides pHK-pKV and Pal-pHK-pKV starting from the pHK sequence.

Second, Pal-pHK-pKV (Fig. 1) was synthesized by modifying the pHK-pKV sequence with a hydrophobic palmitic acid moiety at the $\mathrm{N}$-terminus. Fig. 1 shows that Pal-pHK-pKV contains distinct regions comprised by the hydrophobic tail and the positively charged amino acid residues. It also should be noted that the methionine $\mathrm{N}$-terminal end of the pHK-pKV peptide contains a hydrophobic side chain.

We hypothesize that the hydrophobic tail of Pal-pHK-pKV can be beneficial for the peptide self-assembly process into nanostructures. When the Pal-pHK-pKV molecules are introduced into a PBS aqueous medium, the hydrophobic portions of the peptide will tend to aggregate in order to minimize their surface area in contact with water, leaving the hydrophilic groups exposed to the aqueous environment. This is the suggested rationale of the Pal-pHK-pKV propensity for self-assembly. Meanwhile, the spatial separation of the charged residues from the hydrophobic ones creates an asymmetry of the Pal-pHK-pKV molecule (peptide amphiphile), which is typical for amphiphilc compounds forming self- assembled nanostructures. It has been emphasized that amphiphilic peptides behave like amphiphilic surfactants. ${ }^{63-65}$ Therefore, hydrophobic interactions and electrostatic repulsions are the major driving forces for the Pal-pHK-PKV conjugates self-assembling in solution.
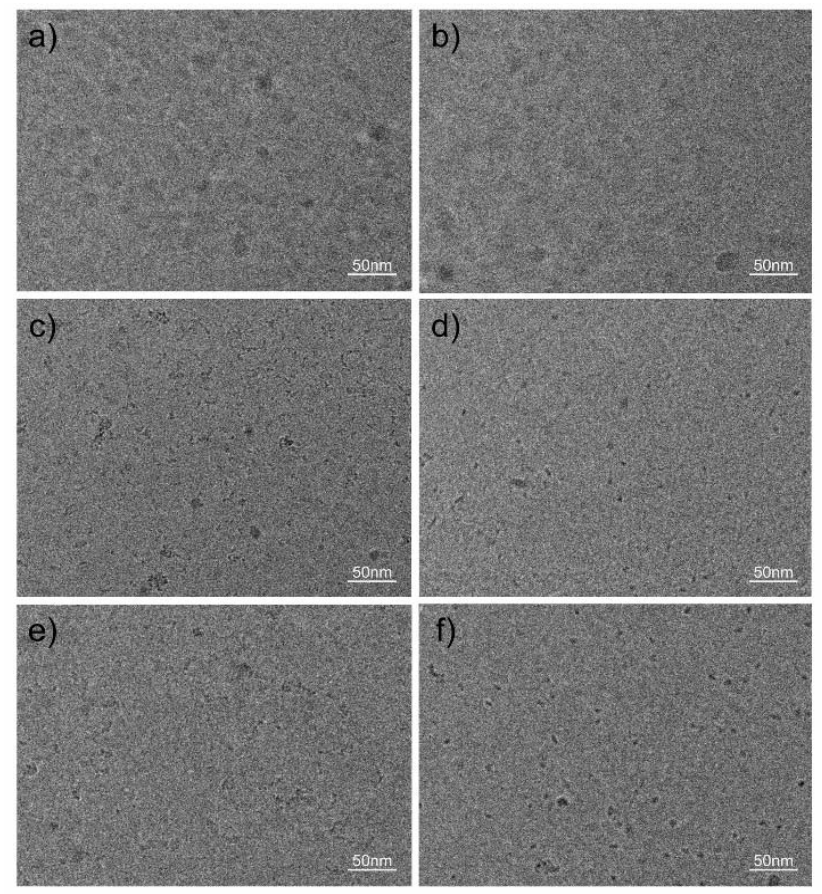

Fig. 2 Cryo-TEM images of the self-assembled nanoarchitectures formed by the peptides at different concentrations; a) $0.3 \mathrm{mM} \mathrm{pHK-}$ pKV; b) $0.3 \mathrm{mM}$ Pal-pHK-pKV; c) $0.9 \mathrm{mM}$ pHK-pKV; d) $0.9 \mathrm{mM}$ Pal-pHKpKV; e) $1.5 \mathrm{mM}$ pHK-pKV; f) $1.5 \mathrm{mM}$ Pal- pHK-pKV.

The self-assembly of pHK-pKV and Pal-pHK-pKV molecules into nanoscale objects was investigated by cryo-TEM imaging at different concentrations (Fig. 2). The image contrast is relatively low due to the lack of electron-rich atoms in the peptide molecules. The small assemblies look as dots in the cryo-TEM images. Aggregates with an average length of $15 \mathrm{~nm}$ are detected for the peptide pHK-pKV at $0.9 \mathrm{mM}$ concentration (Fig. 2c). The images clearly show the formation of supramolecular assemblies at increasing concentrations. The aggregation into visible nanoscale objects begins at 0.3 $\mathrm{mM}$ peptide concentration (Fig. 2a and 2b). At $1.5 \mathrm{mM}$, PalpHK-pKV forms elipsoid-like assemblies (Fig. 2d and 2f).

The self-assembly behaviour of the pHK-pKV and Pal-pHKpKV derivatives was further investigated by synchrotron BioSAXS as a function of the solution concentration (Fig. 3). Both peptide compounds show scattering in the concentration range 0.3-3.0 mM (Fig. $3 a$ and $3 b$ ). Nanostructures are evidenced on the $10-800 \AA$ length scale $\left(1 / q_{\max }-2 \pi / q_{\min }\right)$. Fig.3 demonstrates that both peptide derivatives easily assemble into self-assembled structures. The supramolecular assemblies are formed above a critical concentration for peptide aggregation of about $0.3 \mathrm{mM}$.

The shapes of the BioSAXS curves are similar in the concentration range 0.3-3.0 mM (a whole q-range for Pal-pHKpKV and a large $q$-range interval for pHK-pKV). This indicates 
that the aggregated structures negligibly change with the variation of the concentration under these experimental conditions and it should be possible to compare with in vitro experiments performed under further dilution.

The absence of a plateau of scattering intensity at the lowest $q$-range suggests that there are also structures of larger sizes than the observation window of the performed SAXS measurements, i.e. the scattering from the whole objects is outside the measured scattering vector. The slope $\alpha$ of the scattering intensities $\left(I(q) \sim q^{-\alpha}\right.$ ) plot at the lowest $q$-range is below 1 . This implies that long cylindrical structures are not formed by the self-assembled Pal-pHK-pKV peptide amphiphile. Therefore, we performed fitting of the experimental scattering intensities by a model scattering from a population of ellipsoids of rotation with semi axes $a, b, b$ taking into account excluded volume interactions among the aggregates and polydispersity of size in $a$. SAXS data of pHKpKV samples with concentrations 0.3 and $0.9 \mathrm{mM}$ were fitted only for the interval of large $q$ (Fig. 3a). Details of the analysis are presented in the Supporting Information. Scattering data were satisfactory described and the fitting parameters pointed that the value of semi-axis $b$ increases approximately 2 times by modification of pHK-pKV with a Pal chain. The polydispersity index of axis $a$ increases by dilution of the peptides and the aggregates formed by pHK-pKV are mostly prolate. In parallel, the aggregates of Pal-pHK-pKV are mostly oblate in shape (Table S1).
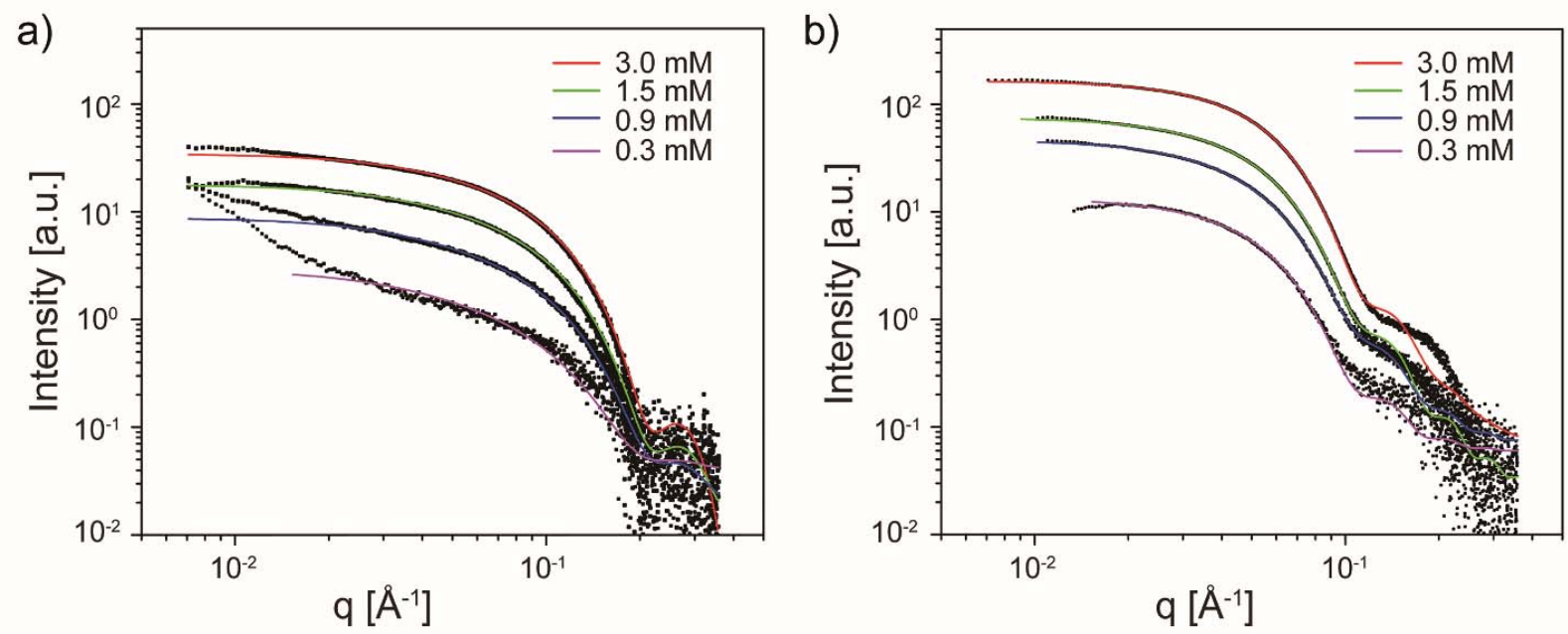

c)

d)
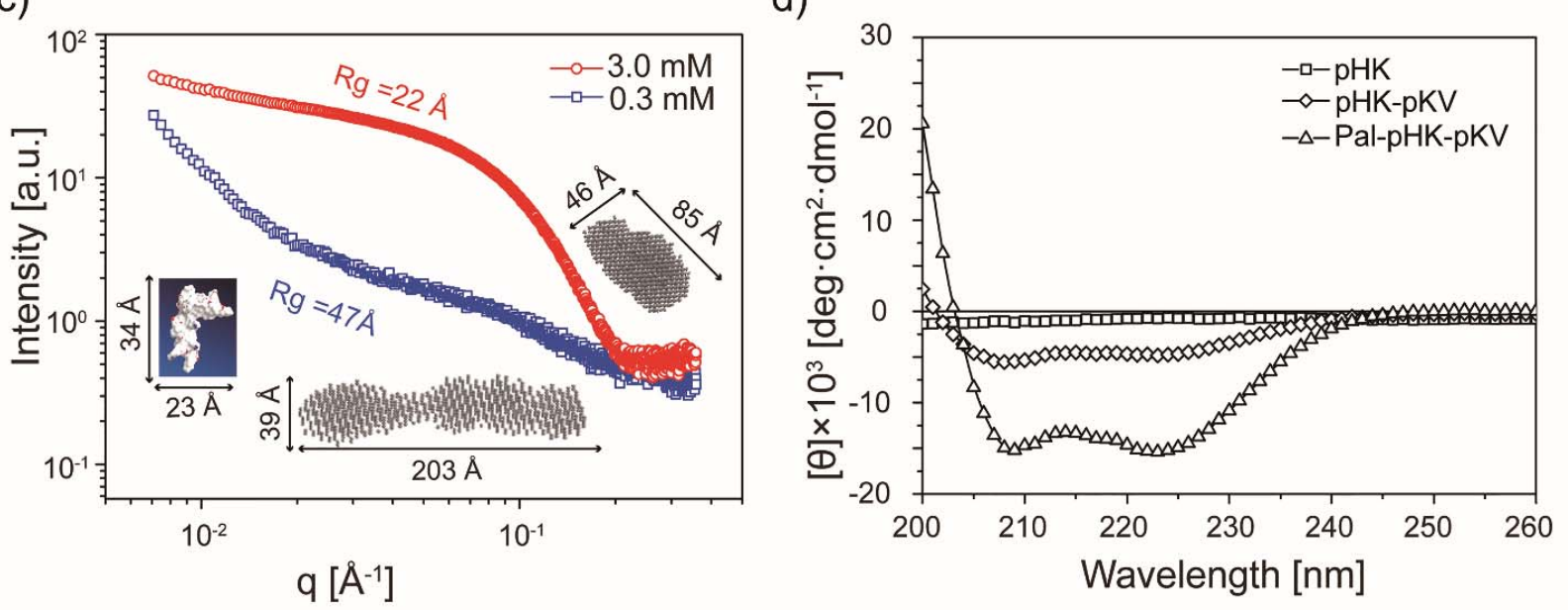

Fig. 3 SAXS patterns of aqueous solutions of (a) pHK-pKV and (b) Pal-pHK-pKV at varying concentrations; (c) Fitting of the BioSAXS curves (line) confirming the presence of elipsoid-like assemblies and showing 3D molecular presentation (left), and derived outer shapes (grayscale) of pHKpKV at $0.3 \mathrm{mM}$ and $3.0 \mathrm{mM}$. (d) The $\mathrm{CD}$ spectra of $0.3 \mathrm{mM}$ pHK, pHK-pKV and Pal-pHK-pKV in aqueous solutions.

Fig.3c presents the performed fitting of the whole scattering curves of the peptide pHK-pKV at the minimal $(0.3$ $\mathrm{mM})$ and at the maximal (3.0 $\mathrm{mM})$ solution concentrations. The shape of the monomeric peptide is shown by a molecular model. pHK-pKV has an extended state dimension of $34 \AA$. The fitting of the scattering curve at $3.0 \mathrm{mM}$ yielded a dimension of the self-assembled pHK-pKV aggregate of $85 \AA$ and a gyration radius $R_{\mathrm{g}}$ of $22 \AA$. The outer shapes of the formed peptide assemblies were determined by the DAMMIN method. ${ }^{87}$ The dilution of the pHK-pKV peptide ( $3.0 \mathrm{mM})$, containing compact ellipsoid-like assemblies, down to a concentration $0.3 \mathrm{mM}$ resulted in more elongated aggregates with a gyration radius 
$\mathrm{R}_{\mathrm{g}}$ of $47 \AA$. Based on the cryo-TEM results (Fig. 2), it can be suggested that the adopted ellipsoid-like shapes of the selfassembled nano-aggregates may result from the packing of small polydispersed spherical units into bigger objects.

The high Pal-pHK-pKV concentration (above $3.0 \mathrm{mM}$ ) was associated with a significant change in the shape of the scattering curve (Fig. S7). It points to the existence of significant interactions among the formed self-assembled aggregates. This is evidenced by the normalized SAXS plots. The BioSAXS curves acquired at decreasing concentrations of the peptide amphiphiles Pal-pHK-pKV (Fig. S7) indicated that the self-assembled nanostructures do not straight dissociate into monomeric peptides upon dilution. The dilution of the Pal-pHK-pKV peptide assemblies causes only partial dissociation of the nano-objects, which demonstrates their sustained-release properties. It can be concluded that the assembly into supramolecular aggregates increases the peptide stability in the excess aqueous buffer phase. This feature is important for the therapeutic application of Pal-pHKpKV assemblies.

Table 2. A correlation between the $\alpha$-helicity of the peptides and their anti-cancer activity, where the half maximal inhibitory concentration $\left(\mathrm{IC}_{50}\right)$ values are determined from cytotoxicity studies. The helicity percentages are calculated from the CD spectra.

\begin{tabular}{lccc}
\hline Peptide & $\begin{array}{c}{[\theta]_{222}} \\
{\left[\operatorname{deg~cm} \mathrm{dmol}^{-1}\right]}\end{array}$ & $\begin{array}{c}\text { Helicity } \\
{[\%]}\end{array}$ & $\begin{array}{c}\mathrm{IC}_{50} \\
{[\mu \mathrm{M}]}\end{array}$ \\
\hline pHK & -731.4 & 12.8 & $>50$ \\
pHK-pKV & -4708.4 & 20.1 & $21.5 \pm 0.3$ \\
Pal-pHK-pKV & -15280.5 & 53.9 & $6.5 \pm 0.1$ \\
\hline
\end{tabular}

The secondary structures of the peptides were investigated by circular dichroism (CD) spectroscopy (Fig. 3d). The CD spectra of pHK-pKV and Pal-pHK-pKV show double negative peaks at wavelengths $208 \mathrm{~nm}$ and $222 \mathrm{~nm}$, which are characteristic of $\alpha$-helical structures. The quantitative percentages of the peptide conformations were determined by the CDNN deconvolution program. The acquired results indicated that the helicity of $\mathrm{pHK}$ is only $12.8 \%$, whereas the helicity for pHK-pKV and Pal-pHK-pKV ranges from $20.1 \%$ to $53.9 \%$, corresponding to a 1.6 to 4.2 -fold increase (Table 2 ). The significant difference in the helical content suggests that the coupling of a fatty acid tail to the peptide sequence is a strategy, which can stabilize the $\alpha$-helical conformation. The $\alpha$ helical configuration has a higher propensity for interaction and insertion into lipid membranes, respectively for overcoming the membrane barriers.

The $I C_{50}$ values of the peptides, determined from cytotoxicity assays with A549 cancer cells (see the section below), are compared in Table 2. They reveal that the Pal-pHKpKV exhibits a considerably enhanced activity for A549 cells growth inhibition as compared to pHK-pKV, and this correlates with the increased helical content in the peptide conformation. For comparison, the $\mathrm{IC}_{50}$ value of the nonmodified $\mathrm{pHK}$ is higher than $50 \mu \mathrm{M}$. These results imply that the higher peptide helicity, the higher anti-cancer activity of the HK-II derivatives.

\section{Cytotoxicity and apoptosis assays of peptide amphiphiles}

The cytotoxic effects of the designed peptides were determined in human lung cancer cells A549 and human normal colonic epithelial cell Lline NCM460 by MTT assays. The concentration dependence of the cell survival upon different treatments (pHK, pHK-pKV, or Pal-pHK-pKV) was evaluated by a two-way ANOVA.

Treatment of A549 cancer cells by pHK resulted in a negligible change of the cellular viability. At highest $\mathrm{pHK}$ concentration $(50 \mu \mathrm{M})$, over $90 \%$ of the cells were viable after $24 \mathrm{~h}$ incubation (Fig. 4a). This confirmed that that pHK does not have a capacity to permeate the cell membrane and reach the subcellular site of action at the OMM. In contrast, treatment of the A549 cells by pHK-pKV showed a noticeable effect on the cancer cell viability (Fig. 4a). This demonstrated that coupling of pKV to $\mathrm{pHK}$ enhanced the cell penetrating capacity of the peptides in the cancer cells. Treatment with Pal-pHK-pKV also resulted in a more pronounced dosedependent decrease of the cancer cell viability. Compared with pHK and pHK-pKV, Pal-pHK-pKV was significantly more cytotoxic to the cancer A549 cells in the entire concentration range (Fig. 4a). The half maximal inhibitory concentration ( $\left(\mathrm{C}_{50}\right)$ values of pHK-pKV and Pal-pHK-pKV for A549 cancer cells after $24 \mathrm{~h}$ were determined to be $21.5 \pm 0.3 \mu \mathrm{M}$ and $6.5 \pm 0.1 \mu \mathrm{M}$, respectively. Thus, the Pal-pHK-pKV conjugate has a significantly stronger anti-proliferative activity against the human lung cancer cells. This is due to the amphiphilic nature of the cell-penetrating peptide (constituted of hydrophobic and hydrophilic building blocks), which favours stronger interactions of the peptide conjugate with the cell membranes. 
a)

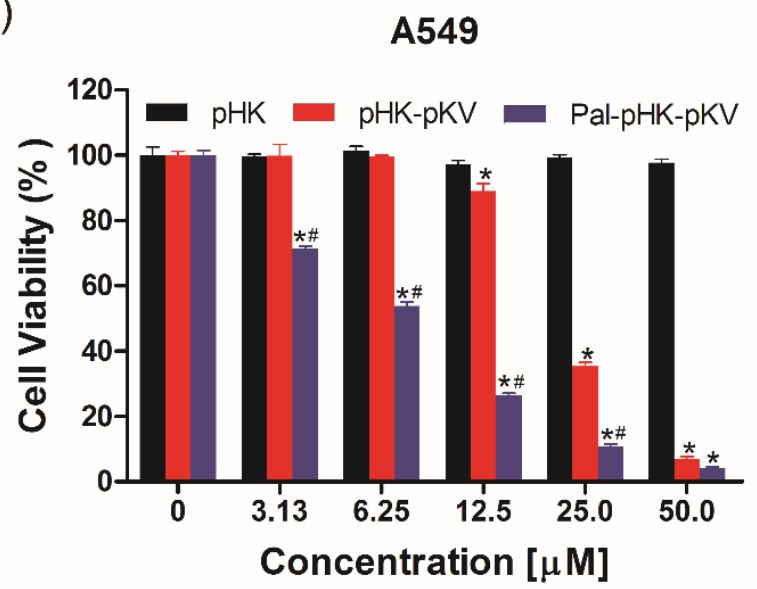

b)

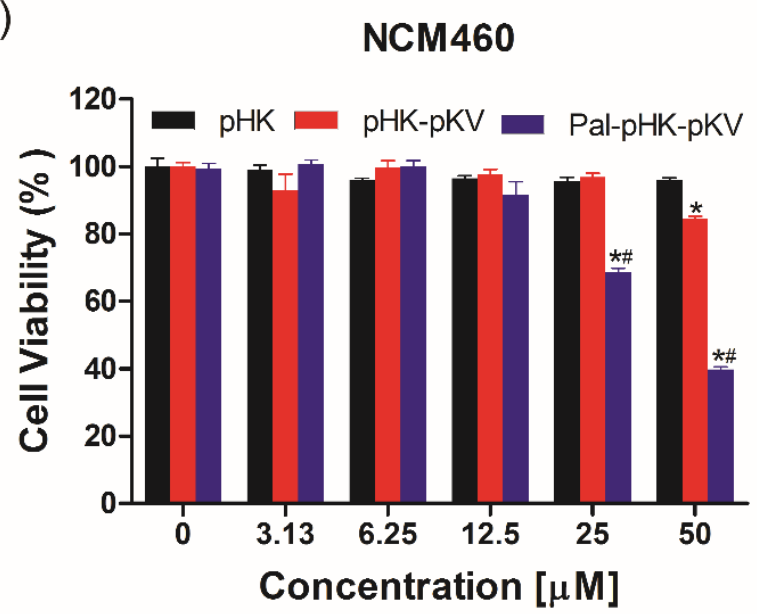

Fig. 4 Investigation of cell viability via MTT assay. a) cancer A549 cells or b) non-cancer NCM460 cells were treated with various concentrations of pHK, pHK-pKV and Pal-pHK-pKV peptides for $24 \mathrm{~h}$. Untreated cells were measured as a control. ${ }^{*} \mathrm{P}<0.05$ compared to $\mathrm{pHK} ;{ }^{\#} \mathrm{P}<0.05$ compared to $\mathrm{pHK}-\mathrm{pKV}$. Data were presented as mean \pm S.E. $(n=3)$.

pHK and pHK-pKV were non-cytotoxic to non-cancerous cells. Treatment by $\mathrm{pHK}$ or $\mathrm{pHK}-\mathrm{pKV}$ resulted in a very slight decrease in the viablity of the non-cancerous NCM460 cells. The conjugate Pal-pHK-pKV was cytotoxic to NCM460 cells only at higher concentrations ( $25 \mu \mathrm{M}$ and $50 \mu \mathrm{M})$. Figure 4 shows that the ability of Pal-pHK-pKV in deterring cancerous A549 cells growth is significantly more profound in comparison to its effect on the non-cancerous NCM460 cells. This can be explained by the fact that its target protein is overexpressed in the OMM of the cancer cells. a)

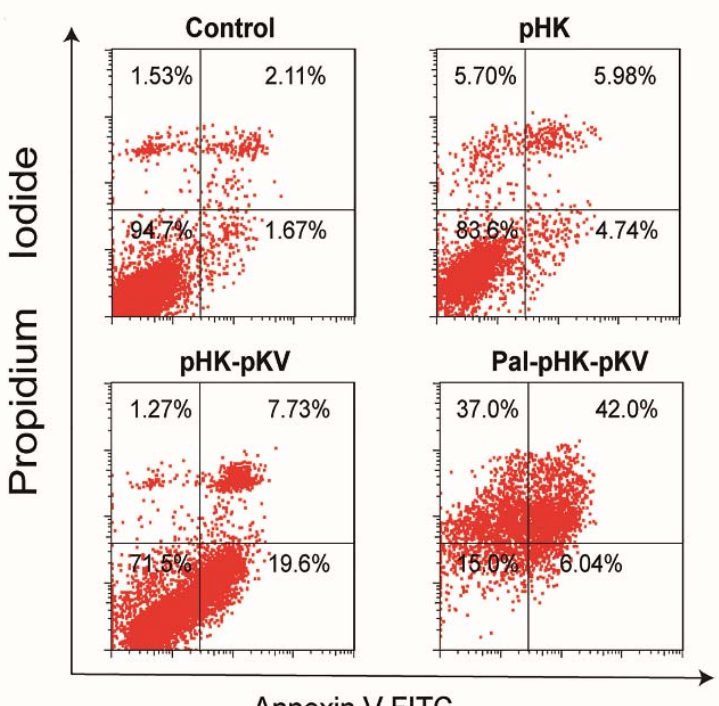

b)

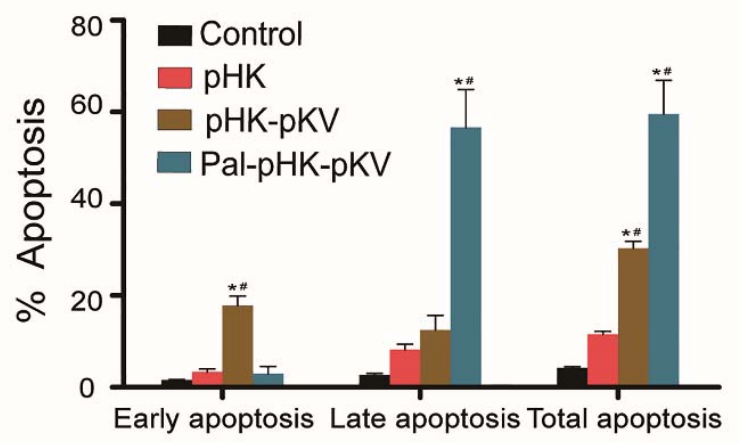

Fig. 5 Flow cytometry (FACS analysis) of annexin V/PI staining of A549 cells that were treated with $12.5 \mu \mathrm{M}$ pHK, pHK-pKV, and Pal-pHK-pKV for $4 \mathrm{~h}$. The bottom left quadrant (annexin $\mathrm{V}^{-} / \mathrm{PI}^{-}$) represents live cells; bottom right (annexin $\mathrm{V}^{+} / \mathrm{PI}^{-}$), early apoptotic cells; top right (annexin $\mathrm{V}^{+} / \mathrm{PI}^{+}$), late apoptotic cells; and top left (annexin $\mathrm{V}^{-} / \mathrm{PI}^{+}$), necrotic cells. b) A summary of the incidence of early apoptosis, late apoptosis and total apoptosis in A549 cells that were treated with pHK, pHK-pKV, and Pal-pHK-pKV determined from FACS analysis of annexin V/PI staining. Untreated cells were measured as a control. ${ }^{*} \mathrm{P}<0.05$ compared to pHK; ${ }^{\#} \mathrm{P}<0.05$ compared to $\mathrm{pHK}-\mathrm{pKV}$. Data were presented as mean \pm S.E. $(n=3)$.

The ability of pHK-pKV and Pal-pHK-pKV in inducing apoptosis/necrosis was examined by a flow cytometry assay using Annexin V/PI (propidium iodide) dual staining (Fig. 5). The A549 cells were treated with $12.5 \mu \mathrm{M}$ formulations of pHK, pHK-pKV, Pal-pHK-pKV for $4 \mathrm{~h}$. Untreated cells were measured as a control. The treatment with pHK resulted in a major fraction of viable cells and a very small number of cells undergoing early and late apoptosis $(4.74 \%$ and $5.98 \%$, respectively). In contrast, the exposure to pHK-pKV and PalpHK-pKV increased the population of late apoptotic cells to $7.73 \%$ and $42 \%$, respectively. These results demonstrated that the cancer cell death induced by pHK-pKV and Pal-pHK-pKV occurs primarily via the apoptosis pathway. The Pal-pHK-pKV assemblies proved to be significantly more efficient in the induction of the apoptosis process, which is followed by cancer cell killing (necrosis) (Fig. 5b).

Therefore, the amphiphilic Pal-pHK-pKV construct has a capacity to amplify the cancer cell death via mitochondria- 
mediated apoptosis. This implies that it has a higher propensity for inducing the dissociation of the hexokinase-II from the outer mitochondrial membrane protein VDAC1. This leads to a massive A549 lung cancer cells death and offers new opportunities for development of mitochondria-targeting peptide amphiphiles with augmented cell-membrane transport properties.

It can be suggested that the Pal-pHK-pKV assemblies appear to act as reservoirs for sustained release of VDAC1-HKII targeting agents. These effects hold the weakening of the VDAC1-HK-II interaction and enhance the dissociation of HK-II from VDAC1, which triggers the mitochondria-mediated apoptosis.

Intracellular localization of the peptide amphiphiles to the mitochondria

The intracellular distribution of the peptide scaffolds upon uptake by A549 cells was determined by confocal fluorescence microscopy imaging (Fig. 6). To visualize the location of the peptide assemblies, the C-termini of the pHK, pHK-pKV, and Pal-pHK-pKV were labelled by the 7-amino-4-methylcoumarin (AMC) dye, which shows a blue fluorescence signal upon excitation by a laser. The A549 cells were incubated with 25 $\mu \mathrm{M}$ formulations of the pHK-AMC, pHK-pKV-AMC and Pal-pHKpKV-AMC derivatives (Table 1 ) for 30 minutes at $37^{\circ} \mathrm{C}$. The mitochondria was stained using a MitoTracker ${ }^{\circledR}$ Red dye as an intracellular organelle marker.

Compared with pHK-pKV-AMC and Pal-pHK-pKV-AMC, the A549 cells treated with the pHK-AMC peptide alone did not show well-detectable fluorescence signal in the intracellular space (Fig. 6a). This is due to the negligibly small cellular uptake of pHK. In contrast, the cellular uptake considerably increased for the pHK-pKV-AMC (Fig. 6b) and Pal-pHK-pKVAMC (Fig. 6c) peptide amphiphiles. The cancer cells incubated with these derivatives displayed intensive blue fluorescence signals in the intracellular space, which is in agreement with the flow cytometry results. The comparison of the distribution of the blue fluorescence patterns of the AMC-labelled peptide assemblies and the red fluorescence of the mitochondriatargeting dye in cells treated by pHK-pKV-AMC and Pal-pHKpKV-AMC gave an evidence for the co-localization with the mitochondria organelles.

The confocal microscopy imaging confirmed the mitochondria-mediated mechanism of apoptotic action of the investigated peptide assemblies. Evidently, the observed enhanced intracellular uptake and the efficient mitochondrial targeting are related to the structural features of the novel peptide amphiphiles. 


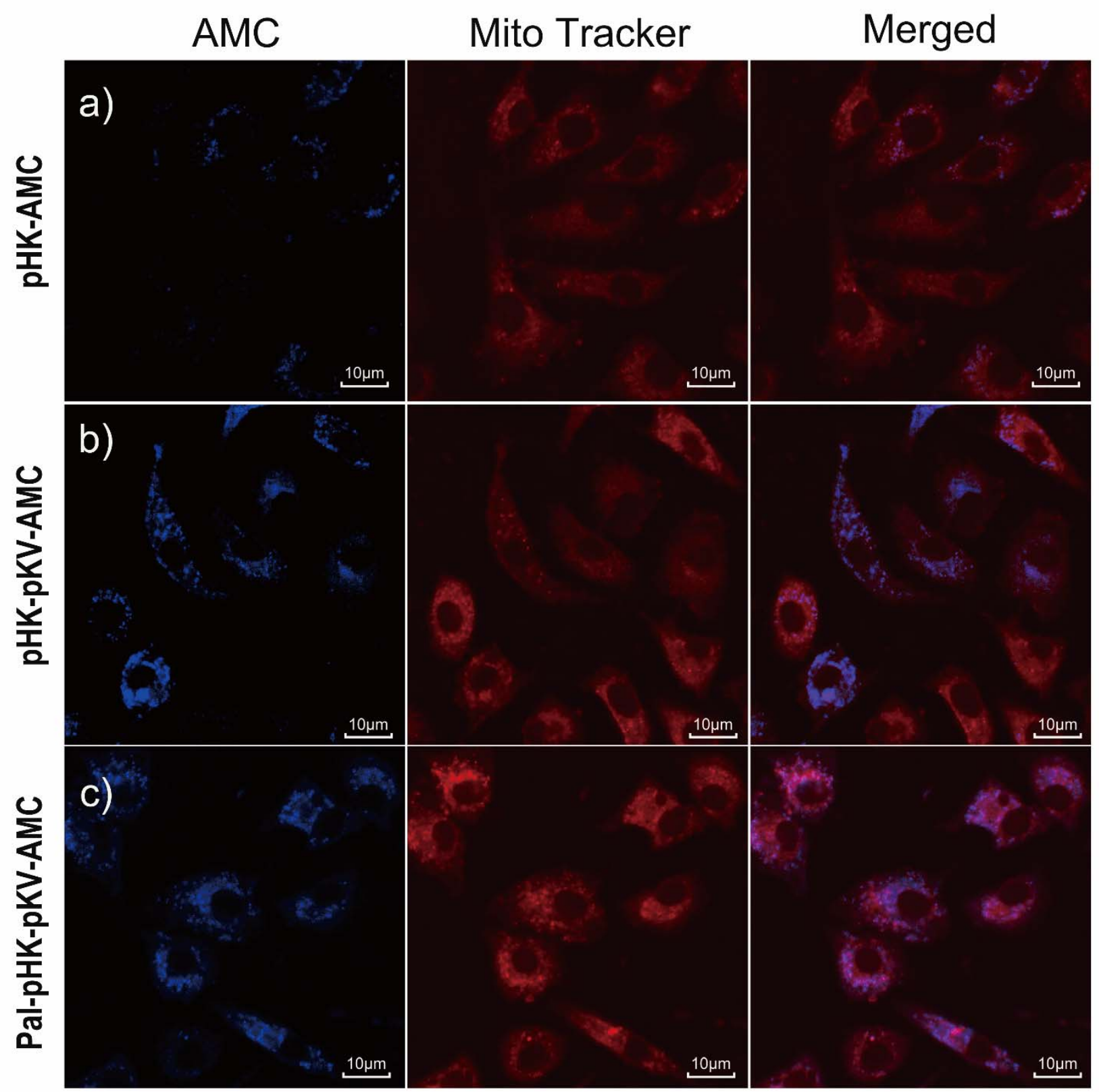

Fig. 6 Confocal fluorescence images of A549 cells incubated with $25 \mu \mathrm{M}$ pHK-AMC, pHK-pKV-AMC and Pal-pHK-pKV-AMC for 30 minutes. The blue fluorescence indicates the uptake of the AMC-labelled peptides. The mitochondria were stained with MitoTracker Red organelle marker (100 nM). The superimposed (merged) images in rows (b) and (c) reveal the co-localization of the HK-II-derived peptides to the mitochondria.

\section{Conclusions}

We found that the mitochondria-specific synthetic peptide amphiphiles pHK-pKV and Pal-pHK-pKV, derived by engineering of the 15 aminoacid terminal fragment of the hexokinase-II protein, self-assemble into supramolecular assemblies. The self-assembly properties arise from the spatial separation of the hydrophobic ( $\mathrm{N}$-terminal) and the charged residue ( $\mathrm{C}$ terminal) building blocks of the molecules. The novel peptide amphiphiles display partial $\alpha$-helix structures. Notably, PalpHK-pKV is characterized by a higher helicity, which suggests a superior affinity for interaction with lipid membranes. The packing of the peptide monomers into oligomeric assemblies yields ellipsoid-like aggregates with nanometric dimensions. The resulting supramolecular peptide assemblies have a considerably higher cytotoxicity to A549 cancer cells as compared to the native $\mathrm{pHK}$ sequence. Both synthetic peptide amphiphiles, pHK-pKV and Pal-pHK-pKV are able to locate to mitochondria and trigger mitochondria-mediated A549 cancer 
cells apoptosis. The obtained results indicate that the selfassembled Pal-pHK-pKV conjugates have an enhanced bioactivity in terms of cell cancer cytotoxicity, degree of cellular uptake, and mitochondrial localization. Therefore, the created self-assembled nanoreservoirs of the peptide Pal-pHKpKV show a potential for development of a promising anticancer therapeutic strategy. Their in vivo drug targeting selectivity should result from the fact that the expression levels of the HK-II target are at least 100-fold greater in the cancer cells as compared to the healthy cells.

\section{Experimental Section}

\section{Materials and Reagents}

Rink-amide resin, protected amino acids, piperidine, N,NDiisopropylethylamine (DIEA), 2-(1H-Benzotriazole-1-yl)1,1,3,3-tetramethyluronium hexafluorophosphate (HBTU), 1hydroxybenzotriazole (HOBt), and 7-amino-4-methylcoumarin (AMC) were obtained from GL Biochem Ltd. (Shanghai, China). Palmitic acid (Pal), Dimethylformamide (DMF), dichloromethane (DCM), Trifluoroacetic acid (TFA, HPLC grade), dimethyl sulfoxide (DMSO), acetonitrile (HPLC grade) and methanol (HPLC grade) were purchased from Aladdin Chemical Reagent Co.Ltd. (China). DMEM medium and Fetal Bovine Serum (FBS) were purchased from GIBCO (Grandland, USA). 3-(4, 5-dimethylthiazol-2-yl)-2, 5-diphenyltetrazolium bromide (MTT) and $0.25 \%$ trypsin-EDTA were purchased from Sigma Aldrich. Annexin V-FITC apoptosis detection kit and a MitoTracker ${ }^{\circledast}$ Red were purchased from Boster Biological Technology Co., Ltd. (China).

\section{Peptide synthesis and purification}

All peptides were synthesized via a solid-phase technique using standard Fmoc chemistry. The conjugation of the peptides with the fluorescent 7-amino-4-methylcoumarin (AMC) dye was done after amide coupling. Reverse-phase high performance liquid chromatography (Agilent 6125B) was employed to purify the crude peptides. HPLC solvents consisted of solvent A ( $0.1 \%$ TFA in acetonitrile) and solvent B (0.1\% TFA in water) and a linear gradient from $10 \%$ to $90 \%$ solvent B was carried out for 25 minutes. The peptide purities were subsequently verified by ESI-MS (Thermo LTQ Oritrap XL equipped with an electrospray ionization source). The results showed that they were synthesized correctly and the purity was $>95 \%$ (Fig. S1-S6).

\section{Circular Dichroism (CD) measurements}

There are no conflicts to declare. The CD spectra of peptides were measured on a Jasco J-810 spectrometer (Jasco Co., Japan) using a quartz cell of $1 \mathrm{~mm}$ path length. The data were recorded from 190 to $260 \mathrm{~nm}$ at a scan rate of $50 \mathrm{~nm} \cdot \mathrm{min}^{-1}$. Peptide samples were diluted from the stock solution to the final concentration $(0.3 \mathrm{mM})$ in PBS $(0.01 \mathrm{M}, \mathrm{pH} 7.4)$. Baseline spectra of the solvent served as the background. The measurements were performed three times at room temperature. The mean residue ellipticity was calculated by the equation $[\theta]=\theta \times M /(\mid \times c \times n r)$, where $\theta$ is the ellipticity value (millidegrees); I is the path length of the cell (millimetres); $\mathrm{M}$ is the molar mass of the peptide; $\mathrm{c}$ is the peptide concentration $\left(\mathrm{mg} \cdot \mathrm{mL}^{-1}\right)$; and $\mathrm{nr}$ is the number of aminoacid residues. Secondary structure determinations were done using the CDNN deconvoution program. ${ }^{88-90}$

\section{Cryogenic Transmission Electron Microscopy (Cryo-TEM)}

For Cryo-TEM, a droplet of the sample was placed onto a carbon-coated holey polymer film supported by a copper grid, gently blotted with a filter paper to form a thin liquid film, and instantly plunged into liquid ethane at $-180^{\circ} \mathrm{C}$ for vitrification. The sample grid was then kept at liquid nitrogen temperature and transferred into a Tecnai G2 F20 transmission electron microscope (FEI, USA) operated at $200 \mathrm{kV}$ in zero-loss brightfield mode. Digital images were recorded under low-dose conditions with an eagle $4 \mathrm{k} \times 4 \mathrm{k}$ CCD camera system (FEI, USA).

\section{Small-Angle X-ray Scattering (SAXS)}

SAXS experiments were performed at Shanghai Synchrotron Radiation Facility (Shanghai, China) equipped with a pinhole camera (Molecular Metrology SAXS System). Peptide solutions were loaded into cylindrical quartz capillaries (ID $1.0 \mathrm{~mm}$ ) mounted in a steel holder. A beam size of $0.40 \mathrm{~mm} \times 0.15 \mathrm{~mm}$ at a wavelength of $1.033 \AA$ was adjusted to pass through the centres of the capillaries for every measurement. The exposure time was $1 \mathrm{~s}$ for each sample. Measurements were performed in a momentum transfer range of $7.08 \times 10-3 \AA<q$ $<0.35 \AA$. Collected raw data were analysed using the BioXTAS RAW software package.

\section{Cell culture}

The human lung carcinoma cell line A549 was obtained from the Cell Bank of Type Culture Collection of the Chinese Academy of Sciences (Shanghai, China). The cells were cultured in cell culture dishes containing DMEM medium supplemented with $10 \%(\mathrm{v} / \mathrm{v})$ fetal bovine serum and antibiotics (100 $\mathrm{U} \mathrm{mL}^{-1}$ penicillin and $100 \mathrm{~g} \mathrm{~mL}^{-1}$ streptomycin) at $37{ }^{\circ} \mathrm{C}$ in a humidified $5 \% \mathrm{CO}_{2}$ atmosphere. The $\mathrm{NCM} 460$ cell line has been validated as a control model in antitumor strategies. ${ }^{91}$ The growth medium for the non-cancerous NCM460 cells was

\section{Cytotoxicity assay}

Cell viability was measured by 3-(4, 5-dimethylthiazol-2-yl) - 2, 5-diphenyltetrazolium bromide (MTT) assay. Briefly, cell suspensions were adjusted to a concentration of $5 \times 10^{4}$ cells . $\mathrm{mL}^{-1}$ and then transferred into a 96-well plate, containing medium $(100 \mu \mathrm{L})$. The cells were allowed to adhere in complete medium at $37^{\circ}$ Covernight. After removing the culture medium, the cells were washed with phosphate buffer saline (PBS). Then, serum-free DMEM medium with different concentrations of the peptides (e.g. $0,3.13,6.25,12.5,25$, and $50 \mu \mathrm{M}$ ) was added to each well and further incubated at $37^{\circ} \mathrm{C}$ 
for various times. At the end of incubation, MTT solution $(5 \mathrm{mg}$ . $\mathrm{mL}^{-1}, 10 \mu \mathrm{L}$ ) was added to each well and further incubated at $37^{\circ} \mathrm{C}$ for maximum $4 \mathrm{~h}$. The medium was removed, and the cells were dissolved in dimethylsulfoxide (DMSO). The absorbance was measured at $570 \mathrm{~nm}$. The half maximal inhibitory concentration $\mathrm{IC}_{50}$ values were analyzed using GraphPad Prism (Version 6.0, GraphPad Software).

\section{Flow cytometric analysis of apoptosis and necrosis}

For apoptosis/necrosis staining, the A549 cells were seeded in a 6-well culture plate (SPL Life Sciences Co. Ltd, Korea) at $1 \times 10^{5}$ cells per well and allowed to grow for $24 \mathrm{~h}$. The cells were then subjected to different treatments for $4 \mathrm{~h}$. They were washed twice with cold PBS and collected by centrifugation at $1000 \mathrm{rpm}$ for 5 minutes. According to the instructions of the supplier, the cells were gently resuspended in binding buffer $(200 \mu \mathrm{L})$ and incubated with Annexin V-FITC $(5 \mu \mathrm{L})$ in dark for 15 minutes and of propidium iodide $(10 \mu \mathrm{L})$ for another 5 minutes. All cell samples were immediately analyzed by flow cytometry using a BD FACS Aria Flow Cytometer (BD Biosciences, USA). The FITC-conjugated Annexin $V$ was excited using a $488 \mathrm{~nm}$ laser and the PI was excited using a $561 \mathrm{~nm}$ laser. The fluorescence emissions were recorded at wavelengths $530 \mathrm{~nm}$ and $575 \mathrm{~nm}$ for the FITC-conjugated Annexin $\mathrm{V}$ and $\mathrm{Pl}$, respectively.

\section{Intracellular imaging and co-localization study}

Confocal microscopy imaging was performed in order to investigate the cellular uptake and the intra-cellular distribution of the pHK-pKV and Pal-pHK-pKV assemblies. Briefly, the $A 549$ cells were seeded into a $20 \mathrm{~mm}$ glass bottom dish (In Vitro Scientific, USA) at a density of $4 \times 10^{4}$ cells per $\mathrm{cm}^{2}$ for $24 \mathrm{~h}$ followed by incubation with labelled peptides pHK-pKV-AMC or Pal-pHK-pKV-AMC $(25 \mu \mathrm{M})$ for $30 \mathrm{~min}$. Thereafter, the cells were incubated with MitoTracker ${ }^{\circledR}$ Deep Red FM (100 nM) for 15 minutes in order to stain the mitochondria before being viewed under the confocal fluorescence microscope. The fluorescently labelled peptides and the MitoTracker ${ }^{\circledR}$ Deep Red FM were excited at $405 \mathrm{~nm}$ and $579 \mathrm{~nm}$, respectively. Fluorescence emission was recorded at $455 \mathrm{~nm}$ and $599 \mathrm{~nm}$ for the AMC-labelled peptides and MitoTracker $^{\circledR}$ Deep Red FM, respectively. The imaging was performed on a Nikon A1R confocal laser scanning microscope (Nikon, Japan) using a $\times 100$ Plan-Apo/1.3 NA oil immersion objective with differential interference contrast (DIC) capacity. Image processing was done using Fiji image processing software (Fiji ImageJ, National Institute of Health, Bethesda, MD, USA).

\section{Conflicts of interest}

There are no conflicts to declare.

\section{Acknowledgements}

We gratefully acknowledge the support of this work by the National Natural Science Foundation of China (No. 21573070, 21872051, U1832144), Youth Innovation Promotion Association of Chinese Academy of Science (No. 2017319), and the Czech Science Foundation (GACR project No.17-00973S). SAXS analysis benefited from the use of the SasView application, originally developed under NSF Award DMR0520547. SasView also contains code developed with funding from the EU Horizon 2020 programme under the SINE2020 project (No. 654000).

\section{Notes and references}

1 L. Galluzzi, N. Larochette, N. Zamzami and G. Kroemer, Oncogene, 2006, 25, 4812-4830.

2 S. Farsinejad, Z. Gheisary, S. E. Samani and A. M. Alizadeh, Tumor Biol, 2015, 36, 5715-5725.

3 F. Bray, J. Ferlay, I. Soerjomataram, R. L. Siegel, L. A. Torre and A. Jemal, Ca-Cancer J Clin, 2018, 68, 394-424.

4 M. J. McGuire, B. P. Gray, S. Z. Li, D. Cupka, L. A. Byers, L. Wu, S. Rezaie, Y. H. Liu, N. Pattisapu, J. Issac, T. Oyama, L. X. Diao, J. V. Heymach, X. J. Xie, J. D. Minna and K. C. Brown, Sci RepUk, 2014, 4.

5 C. P. Cerrato, M. Pirisinu, E. N. Vlachos and U. Langel, Faseb J, 2015, 29, 4589-4599.

6 J. Wu, J. S. Li, H. Wang and C. B. Liu, Expert Opin Drug Del, 2018, 15, 951-964.

7 M. F. Cao, J. J. Jiang, Y. F. Du and P. Yan, Mol Med Rep, 2012, 5, 929-934.

8 K. Li, X. X. Lv, F. Hua, H. Lin, W. Sun, W. B. Cao, X. M. Fu, J. Xie, J. J. Yu, Z. Li, H. Liu, M. Z. Han and Z. W. Hu, Int J Cancer, 2014, 134, 692-702.

9 S. Marqus, E. Pirogova and T. J. Piva, J Biomed Sci, 2017, 24.

10 G. J. De, J. K. Ko, T. Tan, H. Zhu, H. C. Li and J. J. Ma, Oncotarget, 2014, 5, 7734-7747.

11 X. F. Cheng, F. Liu, H. Y. Liu, G. J. Wang and H. P. Hao, Biochem Bioph Res Co, 2018, 496, 31-36.

12 E. Pirogova, T. Istivan, E. Gan and I. Cosic, Curr Pharm Biotechno, 2011, 12, 1117-1127.

13 M. Kerkhofs, G. Bultynck, T. Vervliet and G. Monaco, Drug discovery today, 2019, DOI: 10.1016/j.drudis.2019.03.020.

14 S. Reina and V. De Pinto, Curr Med Chem, 2017, 24, 44474469.

15 A. Magri and A. Messina, Curr Med Chem, 2017, 24, 44704487.

16 X. Wang, D. Tang, Y. Zou, X. Wu, Y. Chen, H. Li, S. Chen, Y. Shi and $\mathrm{H}$. Niu, Journal of enzyme inhibition and medicinal chemistry, 2019, 34, 394-404.

17 W. Sun, L. Li, L. J. Li, Q. Q. Yang, Z. R. Zhang and Y. Huang, Acta pharmacologica Sinica, 2017, 38, 806-822.

18 A. Shteinfer-Kuzmine, Z. Amsalem, T. Arif, A. Zooravlov and V. Shoshan-Barmatz, Mol Oncol, 2018, 12, 1077-1103.

19 S. Nashine, P. Cohen, A. B. Nesburn, B. D. Kuppermann and M. C. Kenney, Sci Rep, 2018, 8, 15175.

20 Y. Liu, Q. Li, X. Xiong, Y. Huang and Z. Zhou, Journal of Materials Chemistry B, 2018, 6, 7674-7683.

21 M. T. Jeena, L. Palanikumar, E. M. Go, I. Kim, M. G. Kang, S. Lee, S. Park, H. Choi, C. Kim, S. M. Jin, S. C. Bae, H. W. Rhee, E. Lee, S. K. Kwak and J. H. Ryu, Nature communications, 2017, 8, 26.

22 V. Shoshan-Barmatz, Y. Krelin, A. Shteinfer-Kuzmine and T. Arif, Front Oncol, 2017, 7.

23 V. Shoshan-Barmatz, D. Ben-Hail, L. Admoni, Y. Krelin and S. S. Tripathi, Bba-Biomembranes, 2015, 1848, 2547-2575. 
24 Y. D. Xie, Y. P. Lv, Y. L. Zhang, Z. Z. Liang, L. L. Han and Y. Y. Xie, Biomed Pharmacother, 2019, 109, 679-689.

25 Y. N. Zhao, S. J. Zhang, P. F. Wang, S. N. Fu, D. Wu and A. J. Liu, Cytotechnology, 2017, 69, 851-863.

26 Q. Shen, J. Li, J. H. Mai, Z. Zhang, A. Fisher, X. Y. Wu, Z. Q. Li, M. R. Ramirez, S. Q. Chen and H. F. Shen, Cell Death Dis, 2018, 9.

27 T. Suma, J. W. Cui, M. Mullner, S. W. Fu, J. Tran, K. F. Noi, Y. Ju and F. Caruso, J Am Chem Soc, 2017, 139, 4009-4018.

28 A. G. Levy, P. E. Zage, L. J. Akers, M. L. Ghisoli, Z. Chen, W. Fang, S. Kannan, T. Graham, L. Z. Zeng, A. R. Franklin, P. Huang and P. A. Zweidler-McKay, Invest New Drug, 2012, 30, 191-199.

29 P. L. Pedersen, S. Mathupala, A. Rempel, J. F. Geschwind and Y. H. Ko, Bba-Bioenergetics, 2002, 1555, 14-20.

30 Y. Ma, C. Yu, E. M. Mohamed, H. Shao, L. Wang, G. Sundaresan, J. Zweit, M. Idowu and X. Fang, Oncogene, 2016, 35, 6132-6142.

31 S. P. Mathupala, Y. H. Ko and P. L. Pedersen, Oncogene, 2006, 25, 4777-4786.

32 S. P. Mathupala, Y. H. Ko and P. L. Pedersen, Seminars in cancer biology, 2009, 19, 17-24.

33 K. C. Patra, Q. Wang, P. T. Bhaskar, L. Miller, Z. B. Wang, W. Wheaton, N. Chandel, M. Laakso, W. J. Muller, E. L. Allen, A. K. Jha, G. A. Smolen, M. F. Clasquin, R. B. Robey and N. Hay, Cancer Cell, 2013, 24, 213-228.

$34 \mathrm{M}$. Vega, A. Riera, A. Fernandez-Cid, P. Herrero and F. Moreno, J Biol Chem, 2016, 291, 7267-7285.

35 R. B. Robey and N. Hay, Oncogene, 2006, 25, 4683-4696.

36 J. G. Pastorino, N. Shulga and J. B. Hoek, J Biol Chem, 2002, 277, 7610-7618.

37 U. Thamrongwaranggoon, W. Seubwai, C. Phoomak, S. Sangkhamanon, U. Cha'on, T. Boonmars and S. Wongkham, Biochem Bioph Res Co, 2017, 484, 409-415.

38 D. J. Roberts and S. Miyamoto, Cell Death Differ, 2015, 22, 248-257.

39 M. Mamede, T. Higashi, M. Kitaichi, K. Ishizu, T. Ishimori, Y. Nakamoto, K. Yanagihara, M. Li, F. Tanaka, H. Wada, T. Manabe and T. Saga, Neoplasia, 2005, 7, 369-379.

40 W. Li, F. Gao, X. Ma, R. Wang, X. Dong and W. Wang, Oncotarget, 2017, 8, 32586-32599.

41 N. Bryan and K. P. Raisch, Bioscience Rep, 2015, 35

42 L. Arzoine, N. Zilberberg, R. Ben-Romano and V. ShoshanBarmatz, J Biol Chem, 2009, 284, 3946-3955.

43 S. L. Yoong, W. L. Lau, A. Y. Liu, D. Prendergast, H. K. Ho, V. C. K. Yu, C. Lee, W. H. Ang and G. Pastorin, Nanoscale, 2015, 7, 13907-13917.

44 A. D. Woldetsadik, M. C. Vogel, W. M. Rabeh and M. Magzoub, Faseb J, 2017, 31, 2168-2184.

45 G. S. Krasnov, A. A. Dmitriev, V. A. Lakunina, A. A. Kirpiy and A. V. Kudryavtseva, Expert Opin Ther Tar, 2013, 17, 12211233.

46 F. Chiara, D. Castellaro, O. Marin, V. Petronilli, W. S. Brusilow, M. Juhaszova, S. J. Sollott, M. Forte, P. Bernardi and A. Rasola, Plos One, 2008, 3, e1852.

47 N. Habibi, N. Kamaly, A. Memic and H. Shafiee, Nano today, 2016, 11, 41-60.

48 R. Chen, C. Qian, Y. J. Ji, C. Q. Zhu, L. Wu, W. D. Li, X. L. Bi, Y. T. Wang, G. Cao and Z. P. Chen, Adv Funct Mater, 2019, 29.

49 A. V. Birk, S. Y. Liu, Y. Soong, W. Mills, P. Singh, J. D. Warren, S. V. Seshan, J. D. Pardee and H. H. Szeto, J Am Soc Nephrol, 2013, 24, 1250-1261.

50 P. Arukuusk, L. Parnaste, N. Oskolkov, D. M. Copolovici, H. Margus, K. Padari, K. Moll, J. Maslovskaja, R. Tegova, G. Kivi, A. Tover, M. Pooga, M. Ustav and U. Langel, BbaBiomembranes, 2013, 1828, 1365-1373.

51 M. Cai, J. Li, S. F. Lin, X. Y. Chen, J. Huang, X. Y. Jiang, L. Z. Yang and Y. Luo, Curr Eye Res, 2015, 40, 822-829.
52 S. M. Standley, D. J. Toft, H. Cheng, S. Soukasene, J. Chen, S. M. Raja, V. Band, H. Band, V. L. Cryns and S. I. Stupp, Cancer research, 2010, 70, 3020-3026.

53 C. J. Newcomb, S. Sur, J. H. Ortony, O. S. Lee, J. B. Matson, J. Boekhoven, J. M. Yu, G. C. Schatz and S. I. Stupp, Nature communications, 2014, 5, 3321.

54 B. F. Lin, D. Missirlis, D. V. Krogstad and M. Tirrell, Biochemistry, 2012, 51, 4658-4668.

55 H. Cui, M. J. Webber and S. I. Stupp, Biopolymers, 2010, 94, 1-18.

56 A. Dalzini, C. Bergamini, B. Biondi, M. De Zotti, G. Panighel, R. Fato, C. Peggion, M. Bortolus and A. L. Maniero, Scientific reports, 2016, 6.

57 X. L. Liu, R. Cao, S. Wang, J. L. Jia and H. Fei, J Med Chem, 2016, 59, 5238-5247.

58 V. Bellat, R. Ting, T. L. Southard, L. Vandat, H. Molina, J. Fernandez, O. Aras, T. Stokol and B. Law, Adv Funct Mater, 2018, 28.

59 G. B. Qi, Y. J. Gao, L. Wang and H. Wang, Adv Mater, 2018, 30.

60 A. Dehsorkhi, V. Castelletto and I. W. Hamley, J Pept Sci, 2014, 20, 453-467.

61 E. Sikorska, M. Dawgul, K. Greber, E. llowska, A. Pogorzelska and W. Kamysz, Bba-Biomembranes, 2014, 1838, 2625-2634.

62 H. Cui, T. Muraoka, A. G. Cheetham and S. I. Stupp, Nano Lett, 2009, 9, 945-951.

63 R. Xing, C. Yuan, S. Li, J. Song, J. Li and X. Yan, Angewandte Chemie, 2018, 57, 1537-1542.

64 Q. Zou, M. Abbas, L. Zhao, S. Li, G. Shen and X. Yan, J Am Chem Soc, 2017, 139, 1921-1927.

65 J. Wang, K. Liu, R. Xing and X. Yan, Chemical Society reviews, 2016, 45, 5589-5604.

66 S. E. Paramonov, H. W. Jun and J. D. Hartgerink, Journal of the American Chemical Society, 2006, 128, 7291-7298.

67 H. Dong, S. E. Paramonov, L. Aulisa, E. L. Bakota and J. D. Hartgerink, Journal of the American Chemical Society, 2007 129, 12468-12472.

68 S. Eskandari, T. Guerin, I. Toth and R. J. Stephenson, Adv Drug Deliver Rev, 2017, 110, 169-187.

69 T. J. Moyer, J. A. Finbloom, F. Chen, D. J. Toft, V. L. Cryns and S. I. Stupp, J Am Chem Soc, 2014, 136, 14746-14752.

70 H. Zhang, J. B. Fei, X. H. Yan, A. H. Wang and J. B. Li, Adv Funct Mater, 2015, 25, 1193-1204.

71 Y. X. Chen, C. T. Mant, S. W. Farmer, R. E. W. Hancock, M. L. Vasil and R. S. Hodges, J Biol Chem, 2005, 280, 12316-12329.

72 M. Deleu, M. Paquot and T. Nylander, Biophys J, 2008, 94, 2667-2679.

73 A. Yaghmur, P. Laggner, S. G. Zhang and M. Rappolt, Plos One, 2007, 2.

74 Q. T. Liu, Y. D. Dong and B. J. Boyd, Langmuir, 2016, 32, 5155-5161.

75 X. R. Zhou, Y. M. Cao, Q. Zhang, X. B. Tian, H. Dong, L. Chen and S. Z. Luo, Int J Pharmaceut, 2017, 528, 723-731.

76 A. Angelova, B. Angelov, R. Mutafchieva, S. Lesieur and P. Couvreur, Accounts Chem Res, 2011, 44, 147-156.

77 A. P. Jallouk, R. U. Palekar, J. N. Marsh, H. Pan, C. T. N. Pham, P. H. Schlesinger and S. A. Wickline, Bioconjugate chemistry, 2015, 26, 1640-1650.

78 I. D. M. Azmi, J. Ostergaard, S. Sturup, B. Gammelgaard, A. Urtti, S. M. Moghimi and A. Yaghmur, Langmuir, 2018, 34, 6570-6581.

79 L. Boge, H. Bysell, L. Ringstad, D. Wennman, A. Umerska, V. Cassisa, J. Eriksson, M. L. Joly-Guillou, K. Edwards and M. Andersson, Langmuir : the ACS journal of surfaces and colloids, 2016, 32, 4217-4228.

80 L. Zerkoune, S. Lesieur, J. L. Putaux, L. Choisnard, A. Geze, D. Wouessidjewe, B. Angelov, C. Vebert-Nardin, J. Doutch and A. Angelova, Soft Matter, 2016, 12, 7539-7550. 
81 F. Pirolt, O. Glatter and G. Trimmel, Langmuir, 2018, 34, 8379-8387.

82 M. Valldeperas, M. Wisniewska, M. Ram-On, E. Kesselman, D. Danino, T. Nylander and J. Barauskas, Langmuir, 2016, 32 8650-8659.

83 A. Angelova, V. M. Garamus, B. Angelov, Z. F. Tian, Y. W. Li and A. H. Zou, Adv Colloid Interfac, 2017, 249, 331-345.

84 A. H. Zou, Y. W. Li, Y. Y. Chen, A. Angelova, V. M. Garamus, N. $\mathrm{Li}, \mathrm{M}$. Drechsler, B. Angelov and Y. B. Gong, Colloid Surface B, 2017, 153, 310-319.

85 H. M. Abdelaziz, A. O. Elzoghby, M. W. Helmy, M. W. Samaha, J. Y. Fang and M. S. Freag, Int J Nanomed, 2019, 14, 499-517.

86 P. Rice, I. Longden and A. Bleasby, Trends Genet, 2000, 16 276-277.

87 D. I. Svergun, Biophys J, 1999, 76, 2879-2886.

88 R. Bhomia, V. Trivedi, N. J. Coleman and J. C. Mitchell, Journal of pharmaceutical analysis, 2016, 6, 242-248.

89 R. Subramanyam, A. Gollapudi, P. Bonigala, M. Chinnaboina and D. G. Amooru, Journal of photochemistry and photobiology. B, Biology, 2009, 94, 8-12.

90 G. Bohm, R. Muhr and R. Jaenicke, Protein engineering, 1992, 5, 191-195.

91 G. Alcarraz-Vizán, S. Sánchez-Tena, M.P. Moyer, M. Cascante, Biochim Biophys Acta. 2014, 1840, 1634-9. 